\title{
BMJ Open Association between adverse childhood experiences and adult diseases in older adults: a comparative cross-sectional study in Japan and Finland
}

\author{
Airi Amemiya, ${ }^{1}$ Takeo Fujiwara, ${ }^{\circ}{ }^{2}$ Kokoro Shirai, ${ }^{3}$ Katsunori Kondo, ${ }^{4}$ \\ Tuula Oksanen, ${ }^{5}$ Jaana Pentti, ${ }^{6}$ Jussi Vahtera ${ }^{7}$
}

To cite: Amemiya A, Fujiwara T, Shirai K, et al. Association between adverse childhood experiences and adult diseases in older adults: a comparative cross-sectional study in Japan and Finland. BMJ Open 2019;9:e024609. doi:10.1136/ bmjopen-2018-024609

- Prepublication history and additional material for this paper are available online. To view these files, please visit the journal online (http://dx.doi org/10.1136/bmjopen-2018024609).

Received 5 June 2018 Revised 3 May 2019 Accepted 12 June 2019

Check for updates

(C) Author(s) (or their employer(s)) 2019. Re-use permitted under CC BY-NC. No commercial re-use. See rights and permissions. Published by BMJ.

For numbered affiliations see end of article.

Correspondence to Professor Takeo Fujiwara; fujiwara.hlth@tmd.ac.jp

\section{ABSTRACT}

Objective We aimed to examine the association between adverse childhood experiences (ACEs) and diseases in older adults in Japan and Finland.

Design Cross-sectional comparative study.

Setting Data from a gerontological study in Japan and two public health studies in Finland were evaluated.

Participants A total of 13123 adults (mean age, 69.5 years) from Japan and 10353 adults (mean age, 64.4 years) from Finland were included in this study. Logistic regression was used to examine the association of each of, any of and the cumulative number of ACEs (parental divorce, fear of a family member and poverty in childhood; treated as ordered categorical variables) with poor self-rated health (SRH), cancer, heart disease or stroke, diabetes mellitus, smoking and body mass index. Models were adjusted for sex, age, education, marital status and working status.

Results Of the respondents, $50 \%$ of those in Japan and $37 \%$ of those in Finland reported having experienced at least one of the measured ACEs. Number of ACEs was associated with poor SRH in both countries, and the point estimates were similar (OR: $1.35,95 \% \mathrm{Cl}: 1.25$ to 1.46 in Japan; OR: 1.34, 95\% Cl: 1.27 to 1.41 in Finland). Number of ACEs was associated with the prevalence of cancer, heart disease or stroke, diabetes mellitus, current smoking and an increase in body mass index in both countries. Conclusions The association between ACEs and poor $\mathrm{SRH}$, adult diseases and health behaviours was similar among older adults in both Japan and Finland. This international comparative study suggests that the impact of ACEs on health is noteworthy and consistent across cultural and social environments.

\section{INTRODUCTION}

Although there is an increasing number of studies that have investigated the association between adverse childhood experiences (ACEs, such as long-term financial difficulties, parental divorce and fear of a family member), unhealthy behaviours (eg, obesity, alcohol consumption, smoking and lower levels of physical activity), adult diseases (eg, cardiovascular disease, diabetes,
Strength and limitations of this study

- This is an international comparative study that investigated the impact of adverse childhood experiments (ACEs) on the health of older adults in different cultural and social environments (Japan and Finland) using harmonised data.

- The limitation of this study is that it was a cross-sectional study, and therefore differential recall and selection bias cannot be ruled out. Survival bias is also possible because the participants were older adults.

- Another limitation of this study is that the pooled data of the two countries were not accessible, and therefore interactive effects of the countries and ACE on adult health were not clear.

stroke, cancer and depression) and even early death, ${ }^{1-4}$ few studies have investigated whether ACEs has an impact on the health of older adults. Because of the rising number of older adults in the world, it is therefore necessary to elucidate the risk factors for diseases among older people.

Further, to address the impact of ACEs on health of older people, it is also crucial to elucidate the commonality of the association because the pathways linking childhood adversities with adult health are likely to be dependent on cultural or social environments. ${ }^{5-7}$ Therefore, a comparison of countries with different cultural and/or social environments in childhood, but with similar welfare state regimes, may provide further understanding of the underlying mechanisms of ACEs and older adult health. According to a systematic review, most of the recent studies evaluating the impact of multiple ACEs on health were performed in the USA and the UK, with only a few studies conducted in other countries ${ }^{8}$ such as Asia $^{9}$ or Nordic countries. ${ }^{10}{ }^{11}$ Since the USA and the UK are developed countries with high inequality, there is a need to 
confirm the association in developed but relatively equal, egalitarian countries such as Japan or Finland.

Japan (population: approximately 127 million) and Finland (population: approximately 5.5 million) are members of the Organization for Economic Co-operation and Development (OECD). The two countries employ a universal healthcare system ${ }^{12} 13$ and provide free education to those aged 6-15 years. ${ }^{14}$ According to the World Happiness Report, the level of social support received (measured by having someone to count on in trouble) is relatively high in both countries $(92.3 \%$ and $94.8 \%$ in Japan and Finland in 2015, respectively). ${ }^{15}$ However, the two countries differ in terms of equality (eg, the Gini coefficient, a measure that represents the income distribution of a country's residents, ${ }^{16}$ was 0.38 in Japan in 2014 and 0.26 in Finland in 2015). Out of the 37 OECD countries, Japan ranked 22th and Finland ranked 7th in 2015 in terms of equality. ${ }^{17}$ Furthermore, immigration policies in the two countries were different at the time of this study; international migrants made up $1.3 \%$ of the total Japanese population, whereas $6.2 \%$ of the Finnish population were international migrants in $2017 .{ }^{18}$ Moreover, the divorce rate in Japan in 2017 was $1.7 / 1000$ people, ${ }^{19}$ whereas it was 2.5/1000 people in Finland in 2015. ${ }^{20}$ Finally, the prevalence of ACEs also differed between Japan and Finland, with $37 \%$ of participants (mean age of 73 years old) in a Japanese study reporting at least one $\mathrm{ACE}^{21}$ and $61 \%$ of participants (mean age of 48 years old) in a Finnish study reporting at least one ACE. ${ }^{22}$ Corporal punishment is not forbidden in Japan, but in Finland it has been prohibited by law since 1983. In summary, both Japan and Finland are developed and egalitarian countries, but their differences in terms of inequality, immigration percentage, divorce rate or policy on corporal punishment might contribute to the differential impact of ACEs on diseases in older adults. For example, de-etiolated social capital due to inequality ${ }^{23}$ might contribute to stronger impact of ACEs on health in older adults.

Therefore, the purpose of this study was to examine and compare the association between ACEs and adult diseases, including unhealthy behaviours such as smoking, in older adults in Japan and Finland.

\section{METHODS \\ Sample}

The data in this study were collected from surveys conducted among older individuals in Finland and Japan. The Japanese data were from the Japan Gerontological Evaluation Study (JAGES), which comprises community-dwelling individuals aged 65 years and older from 30 municipalities (in 14 municipalities the entire population was surveyed, whereas in the remaining 16 municipalities random sampling was performed) who were not eligible to receive benefits from public long-term care insurance services (eg, those without functional disability). Self-administered survey questionnaires were delivered by post to those who were listed in a ledger and insured for long-term care. The participants of the JAGES might be healthier than the average older Japanese population because one of the inclusion criteria to participate in the JAGES study is that the individuals should not be received long-term care. The data used were from participants aged $\geq 65$ years $(n=137736$, response rate $=71 \%)$, with a fifth randomly chosen and questioned for information on adverse experiences in childhood $(\mathrm{n}=26229)$ in 2013. The participants of the current study were restricted to an age range of $65-74$ years $(n=15070)$. Participants with missing data on any ACEs $(n=1158)$, self-rated health $(\mathrm{SRH})(\mathrm{n}=325)$, body mass index $(\mathrm{BMI})(\mathrm{n}=483)$ and smoking $(\mathrm{n}=163)$ were excluded.

The Finnish data were drawn from two prospective cohort studies: the Finnish Public Sector (FPS) study ${ }^{24}$ and the Health and Social Support (HeSSup) study. ${ }^{25}$ The FPS study included employees representing a wide range of occupations working in 10 towns and 6 hospital districts. The participants of the FPS were individuals who were, at the time of the study or had previously been, public sector employees; thus, they did not fully represent the general Finnish population of the same age. The FPS data used in this study were derived from employed and retired participants in the 2008/2009 survey and included information on self-reported ACEs $(n=42877$, response rate $=69 \%$ ). For this study, all FPS study respondents were aged $\geq 60$ years, and those who provided information on any ACEs, SRH, BMI and smoking were selected $(n=7169)$. The HeSSup study targeted a sample representative of the Finnish population in four age groups (20-24, 30-34, 40-44 and 50-54 years) in 1998. Therefore, the participants of the HeSSup may be representative of the Finnish population. ${ }^{26}$ In the 2012 follow-up survey, information on self-reported ACEs was obtained from 11924 participants (response rate $=78 \%$ ). Of them, those in the oldest age group (64-68 years) who provided data on any ACEs, SRH, BMI and smoking were selected $(\mathrm{n}=3184)$. Self-administered survey questionnaires were used in the FPS and HeSSup studies. The two Finnish cohorts were pooled. The studies together included 13123 (6214 men and 6909 women) participants from Japan and 10353 (3201 men and 7152 women) participants from Finland.

The JAGES was approved by the Ethics Committee for Research on Human Subjects at Nihon Fukushi University, Japan (No. 10-05) and the Ethics Committee for Medical Research at the University of Tokyo (No. 10555). The FPS study was approved by the Ethics Committee of the Helsinki and Uusimaa Hospital District and HeSSup study by the joint Ethics Committee of the University of Turku and the Turku University Central Hospital. The studies include ethical approval for secondary analyses. The information on data management and handling is relevant and available for the study administrators in each country. We did not handle any personal identifiers in the analysis. 


\section{Participants and public involvement}

Patients were not involved in the development of the research question, outcome measures, design or conduct of the study.

\section{Measurement of ACEs}

The questions related to ACEs were somewhat different among the three studies, but the variables were harmonised. In short, we assessed three ACEs: (1) parental divorce (the FPS study, HeSSup study and JAGES), (2) fear of a family member (FPS and HeSSup studies)/ witness of domestic violence or physical abuse (JAGES) and (3) financial difficulties in the family (FPS study, HeSSup study and JAGES).

In the JAGES, we assessed ACEs using four questions modified from Felitti's original ACE study ${ }^{1}$ and the World Mental Health survey in Japan. ${ }^{27}$ Respondents were asked if they had experienced the following adversities in their childhood (yes/no): parents' divorce/separation, financial difficulties in the family, being witness to domestic violence or physical abuse. We categorised those who responded having experienced 'being witness to domestic violence' and/or 'physical abuse' as having 'frequent fear of a family member' to make these ACEs comparable with those in the FPS and HeSSup studies. Violence against the child (physical abuse) and the mother (witnessing domestic violence) may both result in 'fear of a family member', and we therefore coded witness of domestic violence or physical abuse as 'fear of a family member'. These ACEs measures have been shown to predict the number of remaining teeth ${ }^{28}$ and higher functional limitation in Japan. ${ }^{29}$ In the FPS and HeSSup studies, we assessed ACEs using three survey questions modified from Statistics Finland's Survey of Living Conditions. ${ }^{30}$ Respondents were asked whether they had experienced the following adversities: parent's divorce/separation, longterm financial difficulties in the family and frequent fear of a family member (the response categories 'no', 'yes' and 'cannot say' were coded as dummy variables), and the findings have been used in other studies to predict the presence of coronary heart disease, ${ }^{31}$ depression ${ }^{31}$ and non-adherence to statin therapy. ${ }^{7}$ The questions regarding each ACE are shown in online supplementary table S1.

For the present study, the three ACEs were analysed both separately and as a summary variable $(0,1,2$ and 3 ACEs).

\section{Measurement of adult health and health behaviours}

Questions on adult health and health behaviours were somewhat different between the countries. In the JAGES, SRH was measured using the question: "How do you feel about your current health status: excellent, good, fair or poor?' Responses were recoded to dichotomous response variables (fair/poor as 0 and excellent/good as 1). A history of being diagnosed with cancer, heart diseases or stroke or diabetes mellitus was self-reported (response categories: 'yes' and 'no'). BMI was calculated as participants' self-reported weight in kilograms divided by height in metres squared. The smoking status (current, former or never) was based on replies to survey questionnaires.

In the FPS and HeSSup studies, SRH was measured through the question: 'How is your current health status?' with five response categories (from 1 (poor) to 5 (excellent)). The responses 'moderate', 'good' and 'excellent' were categorised as good (1), and the other response options as poor $(0)$. Information on cancer was derived from the National Cancer Registry, and prevalent cardiovascular disease (heart disease or stroke) and diabetes mellitus were defined based on the special reimbursement for the medication for these diseases, as obtained from the Social Insurance Institution of Finland. In FPS and HeSSup, we used personal identification codes, assigned to all Finnish citizens, to link the respondents to their records in national health registers. BMI was calculated from self-reported weight and height. Smoking status (current, former and never) was based on survey responses. Questions regarding health and health behaviours are shown in online supplementary table S2.

\section{Covariates}

Education was divided into three levels: (1) 9 years or less, referring to a comprehensive school education in Finland and junior high school education in Japan, (2) 9-12 years, describing post-compulsory secondary general academic and vocational education in Finland and high school or technical college education in Japan and (3) 12 years or more, referring to a university degree in both countries. Marital status was divided into four categories: (1) single, never married and non-cohabiting, (2) widowed, (3) divorced and (4) married or cohabiting with a partner. Working status was divided into two categories: (1) working and (2) retired or never worked (Japan). Regarding working status, those who had never worked were not included in FPS because FPS is a study of individuals who, at the time of study, were, or had previously been, public sector employees and represented a wide range of occupations. Therefore, we combined 'retired and never worked' as 'not working' in Japan to be comparable with the studies in Finland. Missing values were treated as dummy variables.

\section{Statistical analysis}

Logistic regression analysis was performed to examine the association of each ACE, any ACE and the cumulative number of ACEs (eg, 0, 1, 2 and 3 ACEs) with health outcomes. Linear regression analysis was used for BMI. Multinomial logistic regression was used for smoking status. Model 1 was adjusted for age and sex. Model 2 was further adjusted for education, marital status and working status.

The ORs and their 95\% CIs were calculated. Statistical analysis was performed using Stata V.13.1 (StataCor). 


\section{RESULTS}

Table 1 shows the distribution of the variables for each country. The prevalence rates of parental divorce, fear of a family member and childhood poverty were 3\%, $9 \%$ and $47 \%$, respectively, in Japan. In Finland, these proportions were $9 \%, 13 \%$ and $29 \%$, respectively. Of the respondents, $50 \%$ of those in Japan and $37 \%$ of those in Finland reported having experienced at least one ACE. The mean age of the participants and the proportion of men were higher in Japan than in Finland.

As for SRH, the rate of 'poor or fair' was higher in Finland than in Japan (37\% and 14\%, respectively). The prevalence of cancer was similar in both countries; however, the prevalence of heart disease or stroke and diabetes mellitus was higher in Japan. As for BMI, the mean BMI was higher in Finland than in Japan. The distribution of smoking status was similar. In the case of socioeconomic status, $50 \%$ of the people in Finland and $24 \%$ of those in Japan were educated for 12 years or more. Of the participants in Finland, $70 \%$ were currently working, whereas $66 \%$ of those in Japan were currently not working.

Table 2 shows the association between ACEs and SRH and diseases (eg, cancer, heart disease or stroke and diabetes mellitus). For both countries, SRH was associated with each type of ACE and the number of ACEs Interestingly, the point estimates were similar. For example, the OR of the number of ACEs for poor/fair SRH was 1.35 (95\% CI 1.25 to 1.46) in Japan and 1.34 (95\% CI 1.27 to 1.41 ) in Finland, after adjusting the covariates (model 2). The ORs of the number of ACEs for cancer, heart disease or stroke and diabetes mellitus were also similar in both studies in model 2. As for each ACE, fear of a family member showed significant risk for cancer and diabetes in Finland, which was not observed in Japan.

Table 3 shows the associations between ACEs and smoking. Former smoking and current smoking were positively associated with the number of ACEs for both counties, and the ORs were similar. Table 4 shows the association between ACEs and BMI. BMI was positively associated with each type of ACE and with the number of ACEs in Finland. This positive association was also significant in Japan.

\section{DISCUSSION}

To our knowledge, this is the first study that compares the impact of ACEs on health of older adults between two countries. This study showed that elderly individuals in Japan and Finland who had experienced ACEs had worse health profiles (suboptimal SRH and presence of chronic diseases) and more often had biological and behavioural risk factors (high BMI and smoking) than those with no ACEs. The strength of these associations was weak or modest, and similar between the two countries, although careful interpretation is needed because the assessment of ACEs in Japan and Finland was different. The only exception was BMI that showed a more robust association in the Finnish cohorts than in the Japanese cohort.

Our finding that highlights the association between ACEs and poor health among older adults is consistent with those of other studies. The association was weaker compared with those in other studies ${ }^{5-8}$ and this might be due to survival bias as we focused on older adults. Regarding SRH, the association between fear of a family member in childhood (ie, in Japan, it was assessed as witness of intimate partner violence) and poor SRH among older adults was slightly stronger than that for parental divorce or childhood poverty in Japan; however, in Finland, such a difference was not observed. Considering that the prevalence of intimate partner violence in Japan was $0.1 \%$, while $0.25 \%$ in Finland in the OECD report, ${ }^{32}$ this result can be interpreted as the detection of intimate partner violence may not be as adequate in Japan compared with Finland, and thus the problem might be unresolved and showed stronger impact for SRH in older age. Alternatively, physical punishment might be more pervasive in Japan than in Finland ${ }^{33}$; physical punishment is forbidden by law in Finland but not in Japan. Regarding cancer, childhood poverty was associated with cancer among older people in Japan, but this association was not observed in Finland. Childhood poverty in Japan might lead to poverty in older age,$^{29}$ which may result in delays in medical check-ups or consultations. Previous study has shown that adults with lower health literacy, which is more likely to happen among those living in poverty, are less likely to use healthcare services in Japan. ${ }^{34}$

Generally, the strength of these associations was similar between the two countries. The consistency of our results in harmonised cohorts from two different countries suggests that childhood adversities affect health similarly in these two societies. In spite of the differences in the cultural and social environments of older adults in these countries, ${ }^{35} 36$ it is interesting to note that the associations observed were similar. A likely explanation could be the presence of universal healthcare system in these countries which offers adequate medical treatment for diseases over one's lifespan and is likely lead to the attenuation of the impact of ACEs on health later in life. This might explain the lower OR of ACEs for diseases comparing previous studies, because universal healthcare system might be effective to protect older adults with ACEs. In addition, the presence of equal free educational opportunities in both countries may explain the similar impact of ACEs on adult health, as educational attainment can attenuate the impact of ACEs on later health. ${ }^{37}$ The presence of high social support, ${ }^{38}$ cultural engagement, access to trusted adults ${ }^{39}$ in both countries may also attenuate the impact of ACEs on later-life health through the enhancement of resilience, described as the ability to adapt to adverse environment. ${ }^{40}$ The effect of ACEs on health, in different educational or healthcare systems, requires further study. 
Table 1 Characteristics of the study participants

\begin{tabular}{|c|c|c|c|c|c|}
\hline & \multicolumn{2}{|c|}{ Japan (JAGES) ( $n=13123)$} & \multicolumn{2}{|c|}{$\begin{array}{l}\text { Finland (pooled FPS and HeSSup studies) } \\
(\mathrm{n}=10353)\end{array}$} & $P$ value \\
\hline Parental divorce & 336 & 2.6 & 958 & 9.3 & $<0.01^{*}$ \\
\hline Childhood poverty & 6135 & 46.8 & 3013 & 29.1 & $<0.01^{*}$ \\
\hline $\begin{array}{l}\text { Any adverse childhood } \\
\text { experience }\end{array}$ & 6561 & 50.0 & 3852 & 37.2 & $<0.01^{*}$ \\
\hline 0 & 6562 & 50.0 & 6501 & 62.8 & $<0.01^{*}$ \\
\hline 1 & 5517 & 42.0 & 2634 & 25.4 & \\
\hline 2 & 983 & 7.5 & 969 & 9.4 & \\
\hline 3 & 61 & 0.5 & 249 & 2.4 & \\
\hline Female & 6909 & 52.7 & 7152 & 69.1 & \\
\hline \multicolumn{6}{|l|}{ SRH } \\
\hline Poor/fair & 1770 & 13.5 & 3780 & 36.5 & $<0.01^{*}$ \\
\hline Cancer & 460 & 3.5 & 388 & 3.8 & $<0.32^{*}$ \\
\hline Missing & & & 54 & 0.5 & \\
\hline Heart disease or stroke & 1353 & 10.3 & 466 & 4.5 & $<0.01^{*}$ \\
\hline Missing & & & 54 & 0.5 & \\
\hline Diabetes mellitus & 1738 & 13.2 & 714 & 6.9 & $<0.01^{*}$ \\
\hline Missing & & & 54 & 0.5 & \\
\hline$<9$ years & 4395 & 33.5 & 1868 & 18.0 & $<0.01^{*}$ \\
\hline $10-12$ years & 5476 & 41.7 & 3168 & 30.6 & \\
\hline $12+$ years & 3103 & 23.7 & 5234 & 50.6 & \\
\hline Missing & 149 & 1.1 & 83 & 0.8 & \\
\hline \multicolumn{6}{|l|}{ Marital status } \\
\hline Single & 326 & 2.5 & 574 & 5.5 & $<0.01^{*}$ \\
\hline Divorced & 535 & 4.1 & 1414 & 13.7 & \\
\hline Widowed & 1606 & 12.2 & 741 & 7.2 & \\
\hline Married/cohabit & 10441 & 79.6 & 7557 & 73.0 & \\
\hline Missing & 215 & 1.6 & 67 & 0.7 & \\
\hline \multicolumn{6}{|l|}{ Working status } \\
\hline Not working & 8604 & 65.6 & 3092 & 29.9 & $<0.01^{*}$ \\
\hline Working & 4062 & 31.0 & 7230 & 69.8 & \\
\hline Missing & 457 & 3.5 & 31 & 0.3 & \\
\hline
\end{tabular}

${ }^{*}$ Chi-squared test.

†t-test.

BMI, body mass index; FPS, Finnish Public Sector; HeSSup, Health and Social Support; JAGES, Japan Gerontological Evaluation Study;

$\mathrm{SRH}$, self-rated health. 
Table 2 Association between ACEs and poor SRH and diseases among older adults in Japan and Finland

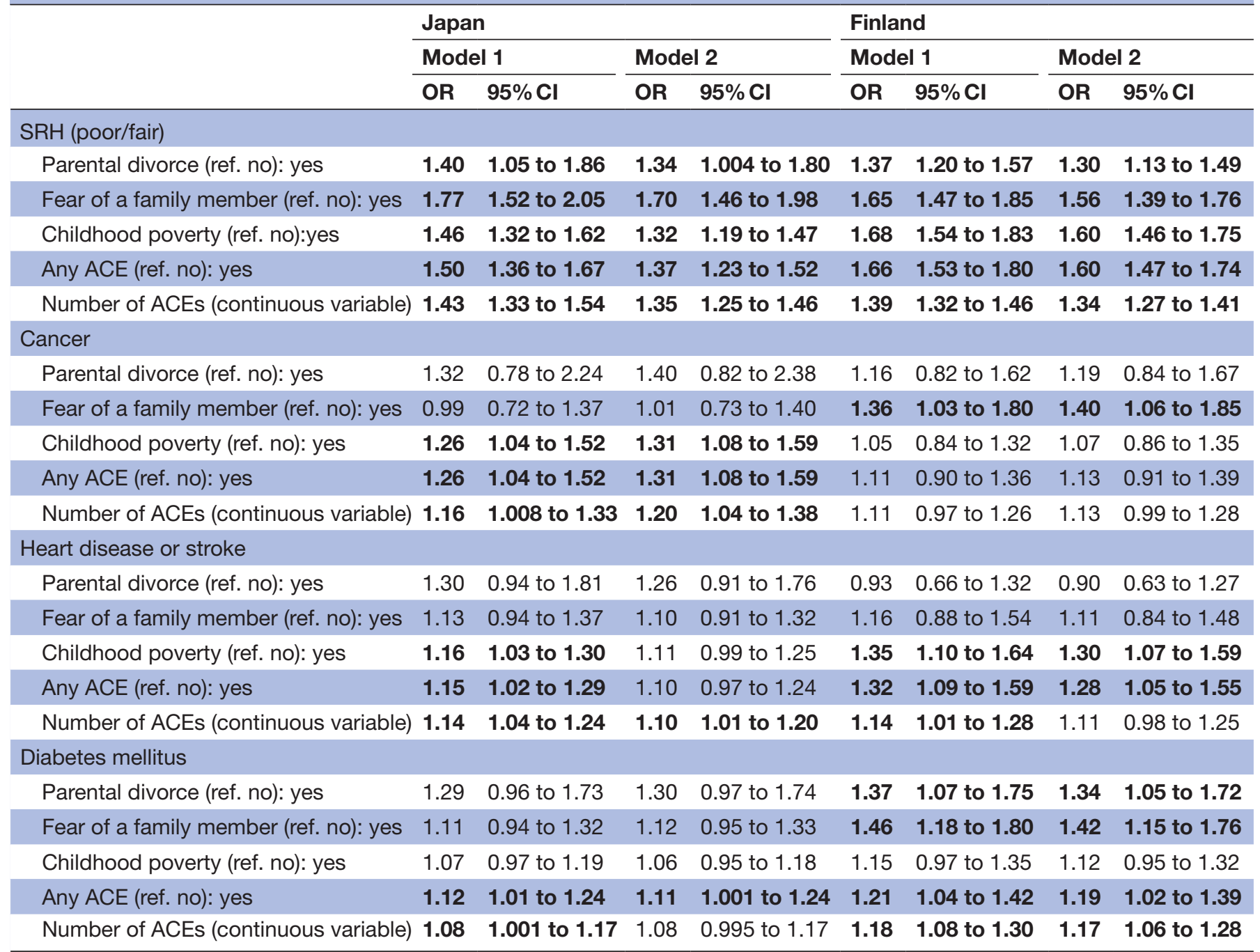

'Any' denotes the presence of at least one ACE.

Model 1: Adjusted for age and sex. Model 2: Further adjusted for education, marital status and working status.

ORs (95\% Cls) were derived from logistic regression models.

Bold text indicates statistically significant with a $p$ value less than 0.05 .

$\mathrm{ACE}$, Adverse childhood experience; ref., reference; $\mathrm{SRH}$, self-rated health.

Similarly, ACEs were associated with smoking, which is consistent with the findings of a previous comparative research in eight Eastern European countries ${ }^{5}$ and other studies in the US, ${ }^{141}$ the $\mathrm{UK}^{42}$ and Finland, ${ }^{43}$ although this association was weak in the current study. The Eastern European comparative study reported that ACEs were associated with smoking among adults aged 14-66 years. ${ }^{5}$ The relationship between ACEs and smoking has predominantly been investigated among adults towards middle age; however, few studies have examined these relationships using large community samples of older adults. Our results suggest that ACEs have a consistent long-term effect on smoking among older adults despite the differences in the price of cigarettes or smoking advertisements between the countries. A meta-analysis showed a moderate OR for smoking among those with four or more ACEs compared with those with no ACEs. ${ }^{8}$ The association was weaker in the current study than that in the meta-analysis, possibly because there were only three ACEs measured in the current study, and the association may have been underestimated because of early death due to smoking and ACEs (eg, survival bias).

ACEs were associated with an increase in BMI in both countries; however, the impact of ACEs was higher in Finland. This association was consistent with that observed in a previous study which showed that ACEs elevated the risk of obesity in the US, ${ }^{12}$ the $\mathrm{UK}^{42}$ and Finland. ${ }^{44}$ The obesity rate among older individuals was higher in Finland than in Japan in the current study; thus, we used continuous BMI as an outcome. The presence of sampling bias in the current study may have also led to the lower impact of ACEs on BMI in Japan, as the JAGES included only individuals without nursing care. 
Table 3 Association between ACEs and former and current smoking among older adults in Japan and Finland

\begin{tabular}{|c|c|c|c|c|c|c|c|c|}
\hline & \multicolumn{4}{|c|}{ Japan } & \multicolumn{4}{|c|}{ Finland } \\
\hline & \multicolumn{2}{|c|}{ Model 1} & \multicolumn{2}{|c|}{ Model 2} & \multicolumn{2}{|c|}{ Model 1} & \multicolumn{2}{|c|}{ Model 2} \\
\hline & OR & $95 \% \mathrm{Cl}$ & OR & $95 \% \mathrm{Cl}$ & OR & $95 \% \mathrm{Cl}$ & OR & $95 \% \mathrm{Cl}$ \\
\hline \multicolumn{9}{|l|}{ Former smoking (ref: never) } \\
\hline Parental divorce (ref. no): Yes & 1.13 & 0.82 to 1.57 & 1.12 & 0.81 to 1.56 & 1.54 & 1.31 to 1.81 & 1.48 & 1.26 to 1.74 \\
\hline Fear of a family member (ref. no): Yes & 1.14 & 0.96 to 1.36 & 1.11 & 0.93 to 1.32 & 1.45 & 1.26 to 1.67 & 1.38 & 1.20 to 1.60 \\
\hline Childhood poverty (ref. no): Yes & 1.14 & 1.02 to 1.26 & 1.13 & 1.02 to 1.26 & 1.42 & 1.28 to 1.57 & 1.37 & 1.24 to 1.53 \\
\hline Any ACE (ref. no): Yes & 1.13 & 1.02 to 1.26 & 1.12 & 1.01 to 1.25 & 1.45 & 1.31 to 1.60 & 1.40 & 1.27 to 1.55 \\
\hline Number of ACEs (continuous variable) & 1.11 & 1.03 to 1.21 & 1.11 & 1.02 to 1.20 & 1.30 & 1.22 to 1.38 & 1.26 & 1.19 to 1.35 \\
\hline \multicolumn{9}{|c|}{ Current smoking (ref: never) } \\
\hline Parental divorce (ref. no): Yes & 1.46 & 1.06 to 2.01 & 1.32 & 0.95 to 1.82 & 1.64 & 1.32 to 2.03 & 1.49 & 1.20 to 1.85 \\
\hline Fear of a family member (ref. no): Yes & 1.29 & 1.07 to 1.55 & 1.16 & 0.96 to 1.40 & 1.45 & 1.19 to 1.76 & 1.32 & 1.09 to 1.61 \\
\hline Childhood poverty (ref. no): Yes & 1.20 & 1.07 to 1.35 & 1.10 & 0.98 to 1.24 & 1.15 & 0.99 to 1.40 & 1.07 & 0.92 to 1.25 \\
\hline Any ACE (ref. no): Yes & 1.24 & 1.10 to 1.39 & 1.13 & 1.01 to 1.27 & 1.33 & 1.16 to 1.53 & 1.24 & 1.08 to 1.43 \\
\hline Number of ACEs (continuous variable) & 1.20 & 1.10 to 1.31 & 1.11 & 1.02 to 1.22 & 1.22 & 1.12 to 1.33 & 1.15 & 1.06 to 1.26 \\
\hline
\end{tabular}

'Any' denotes the presence of at least one ACE.

Model 1: Adjusted for age and sex. Model 2: Further adjusted for education, marital status and working status.

ORs $(95 \% \mathrm{Cls})$ were derived from multinomial logistic regression models.

Bold text indicates statistically significant with a $p$ value less than 0.05 .

ACE, Adverse childhood experience; ref., reference.

On the contrary, 'fear of a family member' showed significant positive association with cancer and diabetes in Finland, which was not observed in Japan. This might be due to the difference in the assessment of fear of a family member. In the Finnish study, it was asked as it is, while in JAGES, witness of domestic violence was used as a proxy measurement of fear of a family member. It may be possible that in Japan, witness of domestic violence may not always induce fear of a family member, say, if the child was used to it. Thus, in Japan the association was weak. Alternatively, fear of a family member may not necessarily be a risk factor for adult disease in Japan because of the rich social network, especially among kin relatives, ${ }^{45}$ which provides an environment for children to escape from a fearful family member. Further study using the same question is needed to confirm whether the discrepancy is due to the difference in the assessment of social environment.

There are several limitations to this study. First, this was a cross-sectional study conducted among older adults. As ACEs were self-reported, differential recall bias cannot be ruled out. Recent review showed poor agreement between prospective and retrospective assessment of childhood maltreatment. ${ }^{47}$ However, in

Table 4 Association between ACEs and body mass index among older adults in Japan and Finland

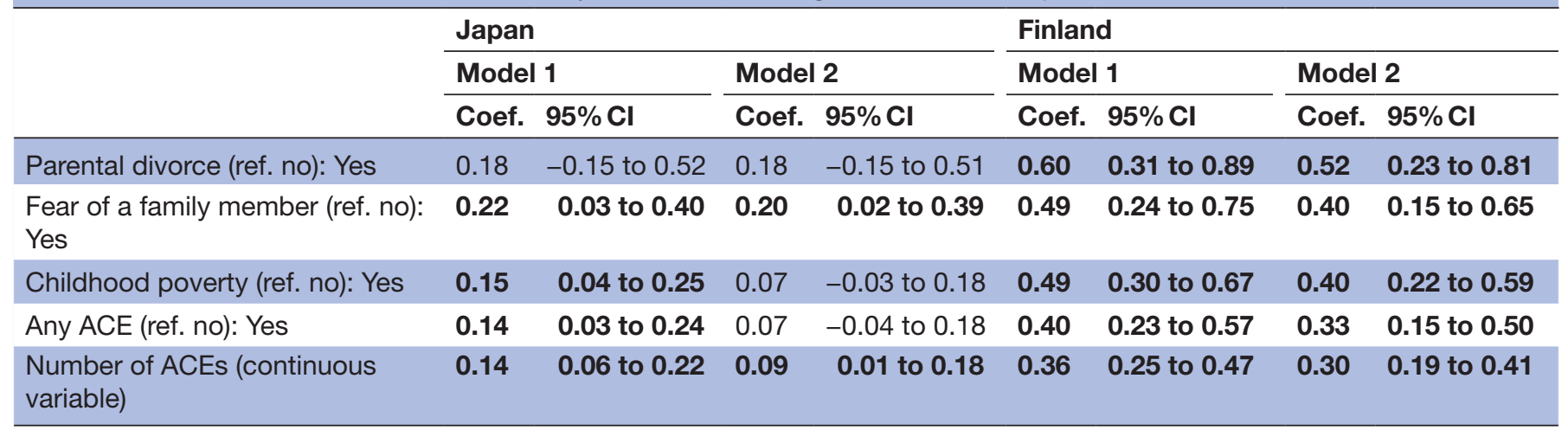

'Any' denotes the presence of at least one ACE.

Model 1: Adjusted for age and sex. Model 2: Further adjusted for education, marital status, and working status.

Coefficients $(95 \% \mathrm{Cls})$ were derived from regression models.

Bold text indicates statistically significant with a $p$ value less than 0.05 .

ACE, Adverse childhood experience; BMI, body mass index; Coef., coefficient. 
contrast, other review studies reported that the validity of retrospective assessment of ACEs is acceptable. ${ }^{48} 49$ Second, these results, although based on harmonised measures, were derived only from two egalitarian developed countries, which preclude the generalisation of the findings to other countries. Further studies are warranted to investigate the association between other ACEs and adult disease in different cultural settings, and in low-income and middle-income countries. Third, we did not assess other ACEs such as sexual abuse, neglect, childhood neighbourhood deprivation or family disfunction (ie, mental disorder of a family member, or incarcerated family member), and thus the number of ACEs were limited only to three. The limited number of ACEs precluded to assess stronger impact of ACEs on adult diseases, as a previous meta-analysis revealed. ${ }^{8}$ Further studies are necessary to investigate the impact of other ACEs on the health of older adults. Fourth, there is a disparity in the measurement of ACEs and health, and ACEs and health behaviours, across the JAGES, FPS and HeSSup. The differences in measurement might result in heterogeneity of the results. More specifically, the assessment of fear of a family member in the JAGES, FPS and HeSSup was different, which may result in heterogeneity between study estimates. Fifth, the participants in the JAGES did not have functional disability, and hence might be healthier than the average Japanese older population. Therefore, the results of the study might be underestimated. Alternatively, the results might be subjected to survival bias. The average age of the study participants was 69.5 years in Japan and 64.4 years in Finland. People who passed away from ACE-related diseases or health risk behaviours before the current study would not have been included in the current study. Therefore, the results of the current study may underestimate the health effects of ACEs. Further, FPS was a not representative sample, and thus the prevalence of diseases, such as cancer, may be different from other studies. Sixth, considering other covariates such as levels of inequality, current and previous household income, environmental risks (eg, parental smoking) or genetic variation was not feasible due to data availability. In fact, education level was higher in the Finnish sample than in the Japanese sample. Finally, we were unable to pool the data of the two countries due to restriction on the Finnish data, and therefore interactive effects of the countries and ACE on adult health were unclear.

Nonetheless, this is the first study that investigated the association between ACEs and health and health behaviour among older people in two countries. In Japan and Finland, the relationship between ACEs and health was similar for SRH, specific diseases and smoking. The impact of ACEs on BMI was stronger in Finland than in Japan. These results suggest a notable association between ACEs and health among older people, and that this association remains consistent even in countries with a different social environment.
Based on these findings, health policy to address ACEs is needed to prevent future diseases among older adults.

\section{Author affiliations}

${ }^{1}$ Department of Health Economics and Epidemiology Research, University of Tokyo School of Public Health, Bunkyo-ku, Japan

${ }^{2}$ Department of Global Health Promotion, Tokyo Medical and Dental University, Bunkyo-ku, Tokyo, Japan

${ }^{3}$ Department of Public Health, Osaka University, Suita, Japan

${ }^{4}$ Center for Preventive Medical Science, Chiba University, Chiba, Japan

${ }^{5}$ Finnish Institute of Occupational Health, Turku, Finland

${ }^{6}$ Department of Public Health, University of Turku, Turku, Turku, Finland

${ }^{7}$ Tyoterveyslaitos, Helsinki, Finland

Contributors TF conceived design; KS, KK, JV collected data; TF, AA, T0, JP, JV analysed data; AA wrote first draft; TF, T0, JV finalised manuscript. All authors approved the final version of the manuscript.

Funding This work was supported by the Japan Society for the Promotion of Science's KAKENHI Grants (grant number JP15H01972 and JP16K16633), Health Labour Sciences Research Grants (grant number H28-Choju-Ippan-002), Research and Development Grants for Longevity Science from the Japan Agency for Medical Research and Development (AMED), Personal Health Record Utilization Project from AMED, Research Funding for Longevity Sciences from the National Center for Geriatrics and Gerontology (grant number 29-42) and the World Health Organization Centre for Health Development (WHO Kobe Centre) (WHO APW 2017/713981). JV was supported by NordForsk (Nordic Research Program on Health and Welfare). T0 received funding from the Finnish Work Environment Fund (grant number 117094).

Competing interests None declared.

Patient consent for publication Not required.

Provenance and peer review Not commissioned; externally peer reviewed.

Data sharing statement The ethics commitee reluctant to share the data.

Open access This is an open access article distributed in accordance with the Creative Commons Attribution Non Commercial (CC BY-NC 4.0) license, which permits others to distribute, remix, adapt, build upon this work non-commercially, and license their derivative works on different terms, provided the original work is properly cited, appropriate credit is given, any changes made indicated, and the use is non-commercial. See: http://creativecommons.org/licenses/by-nc/4.0/.

\section{REFERENCES}

1. Felitti VJ, Anda RF, Nordenberg D, et al. Relationship of childhood abuse and household dysfunction to many of the leading causes of death in adults. The Adverse Childhood Experiences (ACE) Study. Am J Prev Med 1998;14:245-58.

2. Anda RF, Felitti VJ, Bremner JD, et al. The enduring effects of abuse and related adverse experiences in childhood. A convergence of evidence from neurobiology and epidemiology. Eur Arch Psychiatry Clin Neurosci 2006;256:174-86.

3. Nandi A, Glymour MM, Kawachi I, et al. Using marginal structural models to estimate the direct effect of adverse childhood social conditions on onset of heart disease, diabetes, and stroke. Epidemiology 2012;23:223-32.

4. Brown DW, Anda RF, Tiemeier $\mathrm{H}$, et al. Adverse childhood experiences and the risk of premature mortality. Am J Prev Med 2009;37:389-96.

5. Bellis MA, Hughes $\mathrm{K}$, Leckenby $\mathrm{N}$, et al. Adverse childhood experiences and associations with health-harming behaviours in young adults: surveys in eight eastern European countries. Bull World Health Organ 2014;92:641-55.

6. Anda RF, Butchart A, Felitti VJ, et al. Building a framework for global surveillance of the public health implications of adverse childhood experiences. Am J Prev Med 2010;39:93-8.

7. Halonen JI, Stenholm S, Pentti J, et al. Childhood psychosocial adversity and adult neighborhood disadvantage as predictors of cardiovascular disease: a cohort study. Circulation 2015;132:371-9.

8. Hughes K, Bellis MA, Hardcastle KA, et al. The effect of multiple adverse childhood experiences on health: a systematic review and meta-analysis. Lancet Public Health 2017;2:e356-e366.

9. Xiao $\mathrm{Q}$, Dong MX, Yao J, et al. Parental alcoholism, adverse childhood experiences, and later risk of personal alcohol 
abuse among Chinese medical students. Biomed Environ Sci 2008;21:411-9.

10. Pirkola S, Isometsä E, Aro H, et al. Childhood adversities as risk factors for adult mental disorders. Soc Psychiatry Psychiatr Epidemiol 2005;40:769-77.

11. Harkonmäki K, Korkeila K, Vahtera J, et al. Childhood adversities as a predictor of disability retirement. $J$ Epidemiol Community Health 2007;61:479-84.

12. Shibuya K, Hashimoto H, Ikegami N, et al. Future of Japan's system of good health at low cost with equity: beyond universal coverage. Lancet 2011;378:1265-73.

13. Vuorenkosky L, Mladovsky P, Mossialos E. Finland: health system review. Health systems in transition 2008;10:1-168.

14. Cummings WK. Education and equality in Japan: Princeton University Press, 2014.

15. Helliwell J, Layard R, Sachs J. The World Happiness Report: New York: Sustainable Development Solutions Network. 2016 http:// worldhappiness.report/ (Accessed 18 Nov 2016).

16. Yitzhaki S, Schechtman E. Social welfare, relative deprivation, and the gini coefficient. Springer Ser Stat 2013:253-73.

17. OECD. OECD Income Distribution Database (IDD): Gini, poverty, income, methods and concepts. 2016 http://www.oecd.org/social/ income-distribution-database.htm (Accessed 18 Jul 2017).

18. United Nations. International Migration 2017 http://www.un.org/en/ development/desa/population/migration/publications/wallchart/docs/ MigrationWallChart2017.pdf Accessed 27 Aug 2018.

19. Japanese Ministry of Internal Affairs and Communications. Statistical Handbook of Japan. 2017 http://www.stat.go.jp/english/data/ handbook/c0117.html (Accessed 27Aug 2018).

20. eurostat. Marriage and divorce statistics. $2015 \mathrm{https} / / / \mathrm{ec}$.europa. eu/eurostat/statistics-explained/index.php/Marriage_and_divorce_ statistics (Accessed 27 Aug 2018).

21. Amemiya A, Fujiwara T, Murayama $\mathrm{H}$, et al. Adverse childhood experiences and higher-level functional limitations among older Japanese people: results from the JAGES study. J Gerontol A Biol Sci Med Sci 2017 (published Online First: 20 May 2017).

22. Halonen JI, Vahtera J, Kivimäki M, et al. Adverse experiences in childhood, adulthood neighbourhood disadvantage and health behaviours. J Epidemiol Community Health 2014;68:741-6.

23. Kawachi I, Kennedy BP, Lochner K, et al. Social capital, income inequality, and mortality. Am J Public Health 1997;87:1491-8.

24. Laaksonen E, Martikainen P, Lahelma E, et al. Socioeconomic circumstances and common mental disorders among Finnish and British public sector employees: evidence from the Helsinki Health Study and the Whitehall II Study. Int J Epidemiol 2007;36:776-86.

25. Feldt $\mathrm{T}$, Lintula $\mathrm{H}$, Suominen $\mathrm{S}$, et al. Structural validity and temporal stability of the 13-item sense of coherence scale: prospective evidence from the population-based HeSSup study. Qual Life Res 2007;16:483-93.

26. Korkeila K, Suominen S, Ahvenainen J, et al. Non-response and related factors in a nation-wide health survey. Eur J Epidemiol 2001;17:991-9.

27. Fujiwara T, Kawakami N. World Mental Health Japan Survey Group. Association of childhood adversities with the first onset of mental disorders in Japan: results from the World Mental Health Japan, 2002-2004. J Psychiatr Res 2011;45:481-7.

28. Matsuyama Y, Fujiwara T, Aida J, et al. Experience of childhood abuse and later number of remaining teeth in older Japanese: a life-course study from Japan Gerontological Evaluation Study project. Community Dent Oral Epidemiol 2016;44:531-9.

29. Amemiya A, Fujiwara T, Murayama $\mathrm{H}$, et al. Adverse childhood experiences and higher-level functional limitations among older Japanese people: results from the JAGES study. J Gerontol A Biol Sci Med Sci 2018;73:261-6.
30. Rahkonen O, Lahelma E, Huuhka M. Past or present? Childhood living conditions and current socioeconomic status as determinants of adult health. Soc Sci Med 1997;44:327-36.

31. Korkeila J, Vahtera J, Korkeila K, et al. Childhood adversities as predictors of incident coronary heart disease and cerebrovascular disease. Heart 2010;96:298-303.

32. OECD Social Policy Division - Directorate of Employment LaSA. Family Violence. 2013 https://www.oecd.org/els/soc/SF3_4_Family_ violence_Jan2013.pdf.

33. Iwai $\mathrm{H}$. Social tolerance for the use of physical punishment by parents: an analysis of attitude toward physical punishment using JGSS-2008. JGSS Research Series 2010. No.7.

34. Goto E, Ishikawa H, Okuhara T, et al. Relationship of health literacy with utilization of health-care services in a general Japanese population. Prev Med Rep 2019;14:100811.

35. Chartier MJ, Walker JR, Naimark B. Separate and cumulative effects of adverse childhood experiences in predicting adult health and health care utilization. Child Abuse Negl 2010;34:454-64.

36. Fujiwara T, Kondo K, Shirai K, et al. Associations of childhood socioeconomic status and adulthood height with functional limitations among Japanese older people: results from the JAGES 2010 Project. J Gerontol A Biol Sci Med Sci 2014;69:852-9.

37. Tani Y, Fujiwara T, Kondo N, et al. Childhood socioeconomic status and onset of depression among Japanese older adults: the JAGES prospective cohort study. Am J Geriatr Psychiatry 2016;24:717-26.

38. Kuh D, Shlomo YB. A life course approach to chronic disease epidemiology: Oxford University Press, 2004.

39. Bellis MA, Hardcastle K, Ford K, et al. Does continuous trusted adult support in childhood impart life-course resilience against adverse childhood experiences - a retrospective study on adult health-harming behaviours and mental well-being. BMC Psychiatry 2017; $17: 110$

40. Bellis MA, Hughes K, Ford K, et al. Adverse childhood experiences and sources of childhood resilience: a retrospective study of their combined relationships with child health and educational attendance. BMC Public Health 2018;18:792.

41. Runsten S, Korkeila K, Koskenvuo M, et al. Can social support alleviate inflammation associated with childhood adversities? Nord $\mathrm{J}$ Psychiatry 2014;68:137-44.

42. Anda RF, Croft JB, Felitti VJ, et al. Adverse childhood experiences and smoking during adolescence and adulthood. JAMA 1999:282:1652-8.

43. Bellis MA, Lowey $\mathrm{H}$, Leckenby $\mathrm{N}$, et al. Adverse childhood experiences: retrospective study to determine their impact on adult health behaviours and health outcomes in a UK population. J Public Health 2014;36:81-91.

44. Kestilä L, Koskinen S, Martelin T, et al. Influence of parental education, childhood adversities, and current living conditions on daily smoking in early adulthood. Eur J Public Health 2006;16:617-26.

45. Nonoyama $\mathrm{H}$. The family and family sociology in Japan. Am Sociol 2000;31:27-41.

46. Ochiai E. Sekaino Nakano Sengo Nihon Kazoku (in Japanese). Rekishi Kenkyu Kai Nihonshi Kenkyu Kai, ed. Nihonshi Koza 10 Sengo Nihonron. Tokyo: Univeristy of Tokyo Press, 2005.

47. Baldwin JR, Reuben A, Newbury JB, et al. Agreement between prospective and retrospective measures of childhood maltreatment: a systematic review and meta-analysis. JAMA Psychiatry 2019 (published Online First: 31 Mar 2019).

48. Hardt J, Rutter M. Validity of adult retrospective reports of adverse childhood experiences: review of the evidence. J Child Psychol Psychiatry 2004;45:260-73.

49. Reuben A, Moffitt TE, Caspi A, et al. Lest we forget: comparing retrospective and prospective assessments of adverse childhood experiences in the prediction of adult health. J Child Psychol Psychiatry 2016;57:1103-12. 